\title{
Rejection and Acceptance Across Contexts: Parents and Peers as Risks and Buffers for Early Adolescent Psychopathology. The TRAILS Study
}

\author{
Miranda Sentse • Siegwart Lindenberg • \\ Annelies Omvlee • Johan Ormel • René Veenstra
}

Published online: 26 August 2009

(C) The Author(s) 2009. This article is published with open access at Springerlink.com

\begin{abstract}
In a large sample of early adolescents (T2: $n=$ $1023 ; M$ age $=13.51 ; 55.5 \%$ girls) it was investigated whether the effects of parental and peer acceptance and rejection on psychopathology (externalizing and internalizing problems) remain when taking into account both contexts simultaneously. Moreover, we examined whether acceptance in one context can buffer rejection in the other. It was found that when analyzing peer and parent effects simultaneously (1) the protective effect of parental acceptance and the risk effect of peer rejection were diminished; (2) the protective effect of peer acceptance and the riskeffect of parental rejection remained strong; and (3) peer acceptance buffered parental rejection but parental acceptance did not buffer peer rejection. The results imply that the parent and peer contexts are interdependent. Implications and directions for future research are given.
\end{abstract}

Keywords Parental rejection - Parental acceptance .

Peer rejection $\cdot$ Peer acceptance $\cdot$ Risk-buffering effects

One of the most important human needs in life is the need to belong. Due to the rapidly changing social environment in adolescence, the need to belong is not truly satisfied yet

\footnotetext{
M. Sentse $(\bowtie) \cdot S$. Lindenberg $\cdot$ A. Omvlee $\cdot$ R. Veenstra Department of Sociology/ICS, University of Groningen, Grote Rozenstraat 31,

9712 TG Groningen, the Netherlands

e-mail: m.sentse@rug.nl
}

M. Sentse $\cdot$ J. Ormel

Department of Psychiatry, University Medical Center Groningen, Groningen, the Netherlands

\section{R. Veenstra}

Department of Psychology, University of Turku,

Turku, Finland important to fulfill (Patrick et al. 2007). Belongingness is seen as a fundamental motivation that drives people to gain enduring, positive relationships with significant others (Baumeister and Leary 1995). For early adolescents, the most important and close-by attachment figures are their parents and peers. Reflecting this, being accepted by parents is found to be strongly related to adolescent adjustment (Rohner and Britner 2002; Rothbaum and Weisz 1994), as is being accepted by peers (Hartup 1996). Conversely, being rejected by parents or peers has been associated with emotional and behavioral maladjustment such as depression, aggression, and suicidal behaviors (e.g., Fotti et al. 2006; Loeber and Stouthamerloeber 1986; Parker and Asher 1987). These findings are consistent with the notion that a lack of belonging to others is maladaptive.

Interestingly, despite the bulk of research into the effects of parental acceptance and rejection and peer acceptance and rejection, the question whether attachment figures can substitute each other is still unanswered. Most researchers on adolescent maladjustment have focused either on relations with parents or peers. As a result, it is relatively unclear whether one context (e.g., parents) still has the same impact when taking into account another context (e.g., peers). Therefore, in the current study we will focus on the separate and simultaneous effects of parent and peer relations (acceptance and rejection) on early adolescent externalizing and internalizing problems. Moreover, we aim to find out whether the effects of the parent and peer context can enhance or buffer each other.

\section{Parental Acceptance and Rejection}

The importance of the parent-child relation is a commonly held assumption and theoretically acknowledged by attach- 
ment theorists. According to Bowlby (1973), parents' sensitivity and responsiveness causes children to form mental representations (i.e., internal working models) of the parent as reliable and trustworthy and of the self as worthy of love. The theoretical implication of internal working models in the attachment theory of Bowlby is that ongoing parental rejection makes the child hesitant, aggressive, and hostile toward others because of the chance of rejection. It also causes the child to feel unworthy of love, resulting in impaired self-esteem, depressive feelings, a negative world view, and so on (Rohner 2004). In other words, negative experiences such as parental rejection create mental representations that are distorted, which subsequently influence the way situations and behavior of others are interpreted (Crick and Dodge 1994). The mental representations of others, self, and the world are thus reinforcing each other in a vicious cycle. In addition, there is much evidence that parental and child behavior reinforce each other as well (Fanti et al. 2008). Although the present study focuses on the effect of parental behavior on child behavior, it has to be acknowledged that the opposite direction of effects is also likely to exist, that is, child behavior might affect and produce change in parental behavior (see for a short overview: Pettit and Arsiwalla 2008).

Although attachment theorists emphasize the importance of the parent-child bond in early childhood, others have shown that this importance carries over into adolescence. It has been argued that adolescence is a period of stress, conflict, and detachment between parents and their children. This mainly stems from adolescents' need for autonomy, resulting in rebellious behavior of adolescents (e.g., Agnew 2003). Yet, in reviewing the literature on this topic, Steinberg (2001) concluded that most adolescents report having a good relationship with their parents and that, most importantly, conflict is not normative at all in the average family. Whether the individuation process of early adolescents has a negative impact on their relationship with parents depends on how parents react to their autonomy-striving adolescent children. That is, parents have to learn to balance between giving their children the freedom to do what they want and setting rules and limits (see Sentse et al. 2009a).

The combination of being warm, involved, responsive, and strict and consistent in setting rules and limits, also known as authoritative parenting, has been consistently found to be beneficial for various forms of adolescent adjustment (Bronte-Tinkew et al. 2006; Steinberg 2001). In addition, researchers have found that (early) adolescents who are rejected by their parents are at risk for multiple forms of psychological maladjustment, such as aggression, hostility, depression, and a negative worldview (see for a review: Khaleque and Rohner 2002; Sentse et al. 2009b). On the contrary, perceiving love, care, affection, and warmth from parents is related to higher self-esteem, social competence, and lower rates of depression and behavioral problems (Kerns et al. 1996; Robertson and Simons 1989; Rohner and Britner 2002).

\section{Peer Acceptance and Rejection}

When children move into adolescence other attachment figures come to play an important role in their need to be loved, liked, supported, or in general, to belong. According to Giordano (1995), peer relations are attractive for adolescents in realizing a sense of belonging because they are more egalitarian, less controlling, and less judgmental than relations with adults. Reflecting this, in adolescence peers become of increasing importance as "socializing agents" (Buehler 2006; Fuligni and Eccles 1993). For example, after school adolescents spend twice as much time with peers than parents and they rely less on their parents and family for problem solving (Agnew 2003).

Peers can have both positive and negative influences on a variety of adolescent outcomes. Research has shown that peers can influence maladaptive outcomes, such as antisocial behavior (Patterson et al. 1998). It has been consistently shown that the number of delinquent friends is one of the strongest correlates of delinquent behavior in adolescence (Buehler 2006; Laird et al. 2005). Positive peer influences have been found as well. Social support from friends, for example, can enhance a child's self-esteem and academic achievement (Cohen and Wills 1985). Yet, it has to be acknowledged that these correlates can also emerge from reversed causality, pointing to selection rather than influence effects. Most likely, both processes are at work simultaneously.

The concept of peer acceptance-rejection, that is, a child's social standing in a group, is one of the most researched predictors for adjustment. Being accepted by peers provides adolescents with a sense of belonging in the peer group (e.g., Parker and Asher 1993). This saliency of the need to belong to peers is supported by the numerous researchers who have shown that being accepted by peers is important for the social and mental development of adolescents (Buhs and Ladd 2001; Newcomb et al. 1993; Kupersmidt and Coie 1990; Parker and Asher 1987; Rubin et al. 2004). In contrast, being rejected by peers has detrimental effects on the mental and social development of adolescents, and puts them at risk for later emotional and behavioral maladjustment (Kupersmidt and Coie 1990; Parker and Asher 1987; Rubin et al. 1998).

\section{Acceptance and Rejection Across Contexts}

Of particular interest for the current study are the two relationship contexts that early adolescents are mainly 
involved in: the parent and the peer context. One might ask whether parent and peer relationships are, to some extent, interchangeable. Although parent and peer relations differ on several aspects, there is still considerable overlap with regard to the positive effects that can be derived from these relationships (Furman and Buhrmester 1985). More specifically, both relationships provide adolescents with affection, support, and intimacy. This would suggest that the effects of these relationships can be obtained from peers, for example, if they are unavailable in their relationship with parents.

It has been argued, however, that parents and peers do not have the same weight in their impact on adolescent adjustment. On the one hand, researchers have suggested that although during adolescence peers become more and more important, adolescents maintain a good relationship with their parents. In several studies it was found that parent attachment was more strongly related to well-being in adolescence than peer attachment (Greenberg et al. 1983; Raja et al. 1992). On the other hand, in a controversial review article on socialization contexts, Harris (1995) claims that parents have no important long-lasting effects on their child's development. Moreover, she argues that in adolescence peers have the strongest influence and that the absence of peers has more detrimental effects for healthy development than the absence of parents. In a reaction to this, though, researchers have argued that the conclusions by Harris are based on misinterpreted research outcomes on the topic of parental and peer influences. For example, the effects of gene-environment correlations and interactions were in many cases not taken into account, information on parenting might be biased when parents provide the information instead of the children, and peer selection might be mistaken for peer influence (Collins et al. 2000). In other words, an apparently direct influence of peers might actually be caused by underlying influences of genes or parents (Steinberg 2001).

Given the inconsistent findings on the relative impact of the parent and peer context in early adolescence, is it possible that peer acceptance can buffer for rejection by parents, and vice versa? Recently, several researchers have taken an interest in the interaction between the family environment and the peer context. In general, several studies show that the impact of exposure to risks owing to problematic family relationships can be mitigated by the presence of positive peer relationships (Bolger et al. 1998; Criss et al. 2002; Fotti et al. 2006; Gauze et al. 1996; Lansford et al. 2003; Rubin et al. 2004; Schwartz et al. 2000). A study with young children (age 8-9) found that hostile family environments predicted later peer group victimization for children with a low number of friendships, but not for those who had numerous friendships (Schwartz et al. 2000). Similarly, the effect of negative parenting (e.g, harsh discipline) on externalizing behavior was attenuated by positive peer relations for 5 -year olds (Criss et al. 2002) and early adolescents (Lansford et al. 2003). Researchers also found that children from low cohesive or low adaptive families have lower scores on social competence and general self-worth in the absence of a mutual friend than those who have mutual friendships (Gauze et al. 1996). Thus, although most of this research has focused on one specific outcome per study in (mostly) young children, the findings all point to interdependence between the family and the peer context.

\section{The Present Study}

In the present study we were interested in two core aspects of relationships with parents and peers: acceptance and rejection. We treat acceptance and rejection as separate constructs because it can be argued that they are not simply two opposite ends of the same continuum. Firstly, as shown in the previous paragraphs, acceptance and rejection have different implications for child adjustment. Moreover, they may be of differential importance. Thus, the protective effect of positive parenting may change or disappear when controlling for the risk-effect of negative parenting and vice versa (see for example Patterson et al. 1992). Therefore it is interesting to study the two separate constructs simultaneously. Secondly, and more importantly here, children that experience low levels of acceptance and warmth from their parents or those who are not well-liked by their peers, are not necessarily rejected or disliked by parents and peers. Instead, these children are neglected, ignored, or not visible to peers. In line with this argumentation, Coie et al. (1982) provided a highly cited and commonly used method for assessing these dimensions of social standing separately by asking children who they like best and who they like least. Similarly, items to measure parental acceptance are different from items measuring parental rejection, actively asking for indicators of love and support versus indicators of hostility and punishment (e.g., Markus et al. 2003).

The impact of acceptance and rejection were tested separately and simultaneously in relation to early adolescent externalizing and internalizing problems. The main focus was on the cross-context interactions between parental and peer acceptance and rejection. To our knowledge, this is one of the first studies in which the interaction between parental and peer acceptance and rejection on both externalizing and internalizing problems is examined in a sample of early adolescents. Based on the research we discussed above we hypothesized that acceptance protects against and rejection contributes to psychopathology in early adolescence. Building on the expected main effects of acceptance and rejection, we hypothesized 
that effects of parental and peer rejection may reinforce each other in a negative way and that parental and peer acceptance may reinforce each other in a positive way. Lastly, based on studies that found interactions between various variables from the family and peer context we hypothesized that acceptance in one context buffers the effect of rejection in the other context. By this we mean that rejection in one context may be less harmful when being accepted in another context.

We also included gender in the analyses and tested for gender differences in main effects of rejection and interaction effects (three-way interactions). Because research has shown that girls are more sensitive to negative interpersonal communication and depression (Hankin and Abramson 2001; Hale et al. 2005; Nolen-Hoeksema and Girgus 1994) and more likely to have internalizing problems (Twenge and Nolen-Hoeksema 2002), we hypothesized that being rejected by parents or peers has a stronger association with internalizing problems in adolescence for girls than for boys. We have no specific hypotheses on gender differences in the cross-context interactions, but when testing these interactions we trace gender effects in order to see what differences, if any, there are.

\section{Method}

Sample

This study was part of the TRacking Adolescents' Individual Lives Survey (TRAILS), a prospective cohort study of Dutch preadolescents who will be measured biennially until they are at least 25 years old. The present study involved the first (T1) and the second (T2) assessment waves of TRAILS, which ran from March 2001 to July 2002, and September 2003 to December 2004, respectively (De Winter et al., 2005). The TRAILS target sample consisted of preadolescents living in five municipalities in the North of the Netherlands, including both urban and rural areas. Of the children approached for enrollment in the study (i.e. children in these five selected municipalities attending a school that was willing to participate; in all $N=3145$ children from 122 schools, response of schools $90.4 \%$ ), $6.7 \%$ were excluded because of incapability or language problems. That is, children were excluded from the study if they were incapable of participating owing to mental retardation or a serious physical illness or handicap; or if no Dutch-speaking parent or parent surrogate was available and it was not feasible to administer part of the measurements in the parent's language. Of the remaining children, $76.0 \%$ were enrolled in the study, resulting in a sample size of 2230 (of which the actual sample we used in this study is a subsample, see below). Both children and parents actively agreed to participate. A detailed description of the study design, sampling procedures, data collection, and measures of the TRAILS study can be found in De Winter et al. (2005) and Huisman et al (2008).

A peer nominations subsample was used in the present study. The subsample consisted of 1065 of the 2230T1 TRAILS respondents (see also Veenstra et al. 2005). Peer nominations, which were essential for the present study, were only assessed in classrooms with at least ten TRAILS respondents. For this reason, children in school classes with fewer than ten TRAILS respondents were omitted. These children had few TRAILS classmates because our sample is a birth cohort, which made the subsample more selective. Children in special education (5.6\% of the sample), children in small schools $(6.4 \%)$ and children who repeated a grade $(16.9 \%)$ or skipped a grade $(2.2 \%)$ were not included in the subsample. The subsample of 1,065 children (T1: mean age: $11.06, \mathrm{SD}=0.51 ; 55.2 \%$ girls; $8.7 \%$ had at least one parent born in a non-western country; $32.0 \%$ of children had a father and $33.8 \%$ a mother with a low educational level, at maximum a certificate from a lower track of secondary education) differed from the other TRAILS-respondents on several individual and psychosocial characteristics: they were more often girls, $\chi 2(1, n=2230)=16.1, p<0.01)$; came on average from higher socio-economic strata, $\mathrm{t}(2186)=5.1$, $p<0.01)$; lived more often with the same parents throughout their life, $\left.\chi^{2}(1, n=2230)=12.5, p<0.01\right)$; and had a higher level of academic performance, $\mathrm{t}(1923)=5.8, p<0.01)$. In sum, the findings produced using this subsample can only be generalized to a population of preadolescents who attend regular elementary schools and did not repeat grades. Of the 1,065 first wave (T1) peer nomination participants, 96.2\% $(n=1023)$ participated in the second wave (T2) of TRAILS. At T2, the mean age of the children in this subsample was 13.51 years $(S D=0.53)$, and $55.5 \%$ were girls.

\section{Measures}

Peer Rejection and Acceptance The data on peer rejection and peer acceptance were assessed with peer nominations. The assessment of the peer nominations lasted about $15 \mathrm{~min}$ and took place during regular lessons. After brief instructions in which a TRAILS staff member emphasized that information would be kept confidential and that children were not allowed to talk to each other during the assessment, the children received the questionnaire with the names of all classmates listed. The teacher and the TRAILS staff member remained in the classroom during the administration of the peer nominations.

Children were asked which classmates they liked and disliked, for which they could nominate an unlimited number of same-gender and cross-gender classmates. The 
nominations received for being liked and being disliked were divided by the total number of classmates, that is, the maximum number of possible nominations. This way, the scores were transformed into proportions meaning that differences in class-size are taken into account. Scores for peer acceptance (like) and peer rejection (dislike) thus ranged from 0 to 1 . This is the most commonly cited procedure for measuring peer acceptance and rejection, and is highly reliable and valid (cf. Bukowski and Hoza 1989; Coie et al. 1982).

Parental Rejection and Acceptance To assess early adolescents' perceptions of current parental rearing at $\mathrm{T} 1$ we used The Egna Minnen Beträffande Uppfostran (My Memories of Upbringing) for Children [EMBU-C]. The original EMBU-C contained 81 items. Markus et al. (2003) developed a shorter version, which we used. The test-retest stability of this shortened version of the EMBU-C over a 2-month period has been found to be satisfactory $(r=0.78$ or higher; Muris et al. 2003). Markus et al. (2003) have reported on the validity of the EMBU-C, which was found to be good.

The scale for Rejection contained 12 items, with an internal consistency of 0.84 for fathers and 0.83 for mothers. Rejection is characterized by hostility, punishment (physical or not, abusive or not), derogation, and blaming of subject ("Do your parents sometimes punish you even though you haven't done anything wrong?"). Parental acceptance was measured by the scale Emotional Warmth and contained 18 items, with an internal consistency of 0.91 for both fathers and mothers. Emotional Warmth is characterized by giving special attention, praising for approved behavior, unconditional love, and being supportive and affectionately demonstrative ("Do your parents make it obvious that they love you?"). Children could rate the EMBU-C as $1=$ no, never, $2=$ yes, sometimes, $3=$ yes, often, $4=$ yes, almost always. The answers for both parents were highly correlated ( $r \mathrm{~s}=0.67$ for Rejection and 0.79 for Emotional Warmth), so we combined them into one score.

Psychopathology Externalizing and internalizing problems were assessed at T1 and T2 by the Dutch version of the Child Behavior Checklist (CBCL) and the self-report version of this questionnaire, the Youth Self-Report (Achenbach 1991a, b; Verhulst and Achenbach 1995). It contains a list of 112 behavioral and emotional problems, which parents can rate as $0=$ not true, $1=$ somewhat or sometimes true, or $2=$ very or often true in the past 6 months. Test-retest reliabilities of the CBCL and YSR have been found to be good. We constructed the scale Externalizing Problems from items corresponding to Aggressive Behavior and Rule-Breaking Behavior. The scale Internalizing Problems was constructed from the items corresponding to Anxious/Depressed, Withdrawn/Depressed, and Somatic Complaints (cf. Achenbach 1991a). Consistent with other reports (e.g., Achenbach et al. 1987; Verhulst and Van der Ende 1992), the agreement between parent-reported and child-reported problems was only moderate $(r \mathrm{~s}=0.41$ and 0.39 for externalizing and internalizing problems). Yet, problem behavior that is rated as present by both parent and child is assumed to be more severe (more generalized) than problems rated by only one informant. Based on this assumption, we used the mean of the standardized parent and child scores as measures of externalizing and internalizing problems in this study.

\section{Analyses}

Gender differences in the variables were examined using $t$-tests. Bivariate associations between all variables involved in the present study were tested using Pearson correlations, for boys and girls separately. Multiple linear regression analyses were used to test the associations between parental and peer rejection and acceptance at T1 and psychopathology at T2. Firstly, the effects of the parent and the peer context were explored separately. Secondly, a model containing all these effects simultaneously was analyzed to find out whether the effects of one context still hold while controlling for the other context. Finally, cross-context interactions were included in these simultaneous models. All the analyses were performed separately for externalizing and internalizing problems. In answering our research questions we were interested in the long-term effects of acceptance and rejection in late childhood (T1) on psychopathology in early adolescence (T2). To provide a stricter test we also conducted our analyses controlling for T1 psychopathology, thus examining a slightly different question; Are the effects of acceptance and rejection also predictive of change in outcome behavior within a relative short time span?

To ease the interpretation of the coefficients, all continuous variables were standardized to $M=0$ and $S D=$ 1 before they entered the analyses. To provide an impression of the effects and to facilitate interpretation of the interaction effects, we wrote out multiple equations using simple slope analysis (Aiken and West 1991), with low and high levels of the predictors indicating one standard deviation below and above the mean, respectively, while holding all other variables to their sample means.

\section{Results}

\section{Descriptive Statistics}

Table 1 contains the means and standard deviations of predictors and outcome variables, for girls and boys 
Table 1 Means and Standard Deviations of Psychopathology, Parental Rejection and Acceptance, and Peer Rejection and Acceptance, for Girls and Boys

\begin{tabular}{|c|c|c|c|c|c|c|c|c|c|}
\hline \multirow[t]{2}{*}{ Variables } & \multicolumn{3}{|l|}{ Girls } & \multicolumn{3}{|l|}{ Boys } & \multicolumn{3}{|c|}{ Differences } \\
\hline & Mean & $S D$ & $n$ & Mean & $S D$ & $n$ & $t$ & $d f$ & $p$ \\
\hline Externalizing problems $\mathrm{T} 2$ & -0.08 & 0.78 & 557 & 0.04 & 0.77 & 438 & -2.34 & 993 & $<0.05$ \\
\hline Internalizing problems $\mathrm{T} 2$ & 0.12 & 0.87 & 557 & -0.22 & 0.74 & 438 & 6.51 & 993 & $<0.01$ \\
\hline Externalizing problems $\mathrm{T} 1$ & -0.23 & 0.65 & 576 & 0.13 & 0.84 & 455 & -7.79 & 1029 & $<0.01$ \\
\hline Internalizing problems $\mathrm{T} 1$ & 0.00 & 0.79 & 576 & -0.10 & 0.79 & 455 & 1.97 & 1029 & $<0.05$ \\
\hline Parental rejection $\mathrm{T} 1$ & 1.43 & 0.26 & 574 & 1.52 & 0.33 & 452 & -4.62 & 1024 & $<0.01$ \\
\hline Parental acceptance T1 & 3.28 & 0.48 & 574 & 3.15 & 0.51 & 452 & 4.25 & 1024 & $<0.01$ \\
\hline Peer rejection $\mathrm{T} 1$ & 0.10 & 0.11 & 577 & 0.15 & 0.13 & 456 & -6.60 & 1031 & $<0.01$ \\
\hline Peer acceptance T1 & 0.30 & 0.15 & 577 & 0.29 & 0.15 & 456 & 1.64 & 1031 & 0.10 \\
\hline
\end{tabular}

separately. $T$-tests showed that compared to boys, girls had higher levels of internalizing problems and perceived more parental acceptance. In addition, compared to girls, boys had higher levels of externalizing problems and were more rejected by both parents and peers. There were no significant gender differences in peer acceptance.

Table 2 contains the correlations between the variables, above the diagonal for girls and below the diagonal for boys. For both boys and girls, parental rejection was the strongest correlate of psychopathology in early adolescence. Peer relations were associated quite weakly with the outcome variables for both boys and girls. The correlations did not differ significantly between boys and girls with the exception of the correlations between internalizing problems and peer rejection $(z$ difference $=-2.04, p<0.05)$.

\section{Regression Analyses}

We included interactions with gender and cross-context interactions in the full model to test for risk-enhancing and risk-buffering effects. Table 3 contains the unstandardized and standardized regression coefficients for all variables in the simultaneous analyses. The results of the analyses on the main effects of the peer and parental context separately are not included in Table 3, but will be discussed in the text.

Main Effects In the analyses without the peer context, parental rejection and acceptance were both significantly associated with early adolescent externalizing problems ( $\beta=0.23, p<0.01$ and $\beta=-0.08, p<0.01$, respectively). This was also true for peer rejection and acceptance $(\beta=0.10$, $p<0.01$ and $\beta=-0.10, p<0.01$, respectively) when analyzed separately from the parent context. When taking both contexts into account simultaneously, however, the regression coefficients in Table 3 show that parental rejection was highly significant whereas parental acceptance was only marginally significant in relation to externalizing problems. In addition, peer rejection was significantly associated with externalizing problems, whereas peer acceptance was only marginally significantly related.

With internalizing problems, parental rejection and acceptance were both significantly associated $(\beta=0.21, p<$ 0.01 and $\beta=-0.05, p<0.05$, respectively) when analyzed separately from the peer context. Peer acceptance was also significantly associated $(\beta=-0.11, p<0.01)$, whereas peer rejection was significantly related to internalizing problems

Table 2 Correlations Between Psychopathology, Parental Rejection and Acceptance, and Peer Rejection and Acceptance

\begin{tabular}{lllllllll}
\hline Variables & 1 & 2 & 3 & 4 & 5 & 6 & 7 \\
\hline 1. Externalizing problems T2 & - & $0.51^{* *}$ & $0.57^{* *}$ & $0.34^{* *}$ & $0.30^{* *}$ & $-0.18^{* *}$ & $0.14^{* *}$ & $-0.12^{* *}$ \\
2. Internalizing problems T2 & $0.48^{* *}$ & - & $0.33^{* *}$ & $0.53^{* *}$ & $0.30^{* *}$ & $-0.16^{* *}$ & $0.11^{*}$ & $-0.12^{* *}$ \\
3. Externalizing problems T1 & $0.60^{* *}$ & $0.31^{* *}$ & - & $0.56^{* *}$ & $0.44^{* *}$ & $-0.23^{* *}$ & $0.15^{* *}$ & -0.04 \\
4. Internalizing problems T1 & $0.31^{* *}$ & $0.60^{* *}$ & $0.52^{* *}$ & - & $0.38^{* *}$ & $-0.19^{* *}$ & $0.14^{* *}$ & $-0.11^{* *}$ \\
5. Parental rejection T1 & $0.30^{* *}$ & $0.22^{* *}$ & $0.40^{* *}$ & $0.33^{* *}$ & - & $-0.39^{* *}$ & 0.08 & $-0.11^{* *}$ \\
6. Parental acceptance T1 & $-0.16^{* *}$ & -0.06 & $-0.24^{* *}$ & $-0.12^{* *}$ & $-0.33^{* *}$ & - & -0.06 & $0.15^{* *}$ \\
7. Peer rejection T1 & 0.07 & -0.02 & $0.16^{* *}$ & 0.05 & $0.10^{*}$ & -0.07 & - & $-0.30^{* *}$ \\
8. Peer acceptance T1 & $-0.10^{*}$ & -0.07 & $-0.18^{* *}$ & $-0.15^{* *}$ & $-0.16^{* *}$ & $0.11^{*}$ & $-0.42^{* *}$ & - \\
\hline
\end{tabular}

Above the diagonal for girls, below for boys. $N$ ranges from 1018-1065

$* p<0.05, * * p<0.01$ 
Table 3 Regression Analyses of Externalizing and Internalizing Problems on Gender, Parental Rejection and Acceptance, Peer Rejection and Acceptance, and Cross-Context Interactions

\begin{tabular}{|c|c|c|c|c|c|c|c|c|}
\hline \multirow[t]{3}{*}{ Predictors at $\mathrm{T} 1$} & \multicolumn{4}{|c|}{ Externalizing problems $\mathrm{T} 2$} & \multicolumn{4}{|c|}{ Internalizing problems $\mathrm{T} 2$} \\
\hline & \multicolumn{2}{|c|}{$\begin{array}{l}\text { Simultaneous main } \\
\text { effects }\left(R^{2}=0.11\right)\end{array}$} & \multicolumn{2}{|c|}{ Full model $\left(R^{2}=0.12\right)$} & \multicolumn{2}{|c|}{$\begin{array}{l}\text { Simultaneous main } \\
\text { effects }\left(R^{2}=0.11\right)\end{array}$} & \multicolumn{2}{|c|}{ Full model $\left(R^{2}=0.13\right)$} \\
\hline & $b(\mathrm{SE})$ & $\beta$ & $b(\mathrm{SE})$ & $\beta$ & $b(\mathrm{SE})$ & $\beta$ & $b(\mathrm{SE})$ & $\beta$ \\
\hline Gender $(1=$ boys $)$ & $0.04(0.04)$ & 0.02 & $0.04(0.06)$ & 0.02 & $-0.48(0.06)$ & $-0.24 * *$ & $-0.48(0.06)$ & $-0.25 * *$ \\
\hline Parental Rejection & $0.26(0.03)$ & $0.27 * *$ & $0.28(0.05)$ & $0.30^{* *}$ & $0.26(0.03)$ & $0.25 * *$ & $0.36(0.05)$ & $0.35 * *$ \\
\hline Parental Acceptance & $-0.05(0.03)$ & $-0.06^{* * *}$ & $-0.05(0.03)$ & -0.05 & $-0.02(0.03)$ & -0.02 & $0.00(0.03)$ & 0.00 \\
\hline Peer Rejection & $0.08(0.03)$ & $0.08 * *$ & $0.10(0.04)$ & $0.11 *$ & $0.01(0.03)$ & 0.01 & $0.08(0.05)$ & $0.08 * * *$ \\
\hline Peer Acceptance & $-0.05(0.03)$ & $-0.06^{* * *}$ & $-0.06(0.03)$ & $-0.07 *$ & $-0.08(0.03)$ & $-0.08^{*}$ & $-0.09(0.03)$ & $-0.10 * *$ \\
\hline Gender X Parental Rejection & & & $-0.06(0.06)$ & -0.05 & & & $-0.20(0.06)$ & $-0.14 * *$ \\
\hline Gender X Peer Rejection & & & $-0.05(0.06)$ & -0.04 & & & $-0.14(0.06)$ & $-0.10^{*}$ \\
\hline Parental X Peer Rejection & & & $-0.05(0.03)$ & -0.05 & & & $-0.05(0.04)$ & -0.05 \\
\hline Parental X Peer Acceptance & & & $0.02(0.03)$ & 0.02 & & & $0.03(0.03)$ & 0.03 \\
\hline $\begin{array}{l}\text { Parental Acceptance X Peer } \\
\text { Rejection }\end{array}$ & & & $0.01(0.03)$ & 0.01 & & & $-0.03(0.04)$ & -0.03 \\
\hline $\begin{array}{l}\text { Peer Acceptance X Parental } \\
\text { Rejection }\end{array}$ & & & $-0.07(0.03)$ & $-0.07 *$ & & & $-0.07(0.04)$ & $-0.07 *$ \\
\hline
\end{tabular}

Based on $n=1,019$ cases

${ }^{*} p<0.05, * * p<0.01, * * * p<0.10$

only for girls $(\beta=0.11, p<0.01)$ in analyses without the parent context. When the parent and peer context were considered simultaneously, the effects in Table 3 show that parental rejection did and parental acceptance did not relate to early adolescent internalizing problems, whereas peer rejection did not and peer acceptance did significantly relate to internalizing problems.

Gender Interactions Controlling for all other variables, there was no main effect of gender in externalizing problems, nor were there interactions with gender. However, girls were more likely than boys to have internalizing problems in early adolescence and, moreover, the effects of parental and peer rejection were stronger for girls than for boys. Simple slope analyses (Aiken and West 1991) showed that parental rejection was significantly related to internalizing problems for girls and boys, but the effect was stronger for girls $(b=0.36, p<0.01$ versus $b=0.17, p<0.01)$. Peer rejection had a marginally significant effect on internalizing problems for girls $(b=0.08, p=0.08)$, but there was no effect for boys $(b=-0.06, p=0.19)$.

Cross-context Interactions To test for risk-enhancing and risk-buffering effects, cross-context interactions were included in the regression analyses containing all main effects simultaneously. For explorative reasons three-way interactions with acceptance, rejection, and gender were tested as well. Because none of them were significant, they were not included in the tables. Table 3 shows that for both externalizing and internalizing problems there was no risk-enhancing effect of parental and peer rejection, nor was there an enhancing protective effect of parental and peer acceptance. In addition, we found no buffering effect of parental acceptance for peer rejection, but peer acceptance buffered the effect of parental rejection (on both externalizing and internalizing problems: interaction effect $\beta=-0.07, p<0.05)$. To interpret the size of the effect we wrote out multiple equations using simple slope analyses, see Figs. 1 and 2. For externalizing problems, the risk-effect

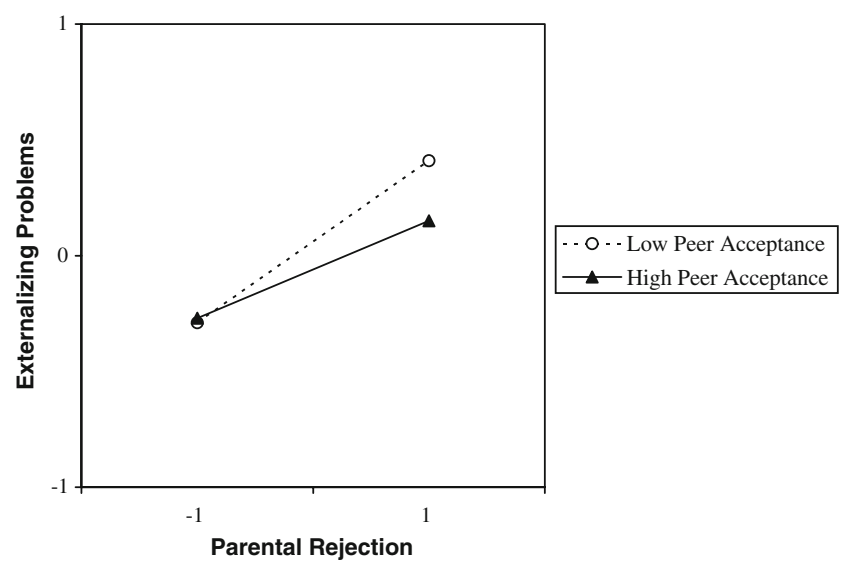

Fig. 1 Interaction between parental rejection and peer acceptance in the prediction of externalizing problems 


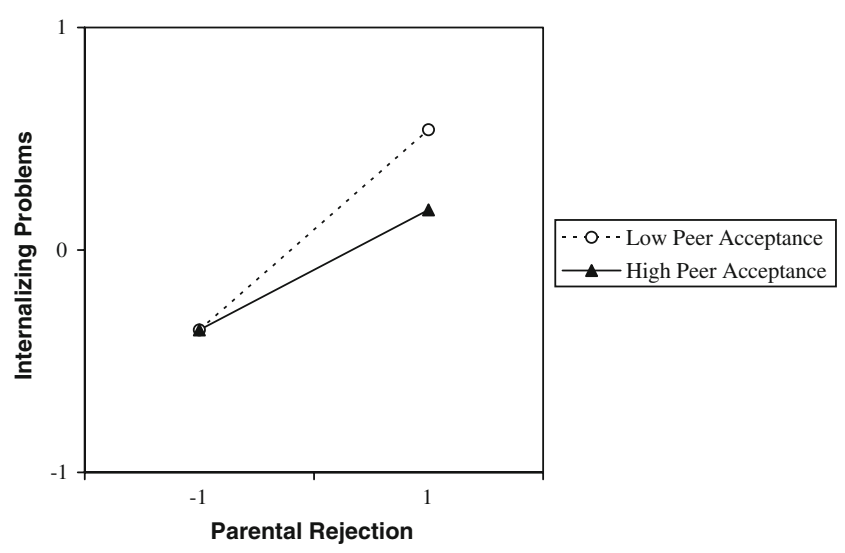

Fig. 2 Interaction between parental rejection and peer acceptance in the prediction of internalizing problems

of parental rejection was higher for children low in peer acceptance $(b=0.35, t(1014)=6.54, p<0.01)$ than for children high in peer acceptance $(b=0.21, t(1014)=3.65$, $p<0.01)$. Likewise, for internalizing problems, the riskeffect of parental rejection was higher for children low in peer acceptance $(b=0.44, t(1014)=7.53, p<0.01)$ than for children high in peer acceptance $(b=0.27, t(1014)=4.41$, $p<0.01)$.

When we performed our analyses controlling for wave 1 psychopathology, we see that parental rejection and peer acceptance are still strongly related to externalizing and internalizing problems. However, the cross-context interaction effects did not hold. Thus, acceptance and rejection and their interaction across contexts are related to psychopathology in early adolescence, but they do not produce change in psychopathology over a 2-year time interval.

\section{Discussion}

The findings of the current study are in line with theories and research on the saliency of the need to belong for early adolescents, both in the parent and the peer context. In examining the relative impact of rejection and acceptance by parents and peers on early adolescent externalizing and internalizing problems, this study adds to the extant literature that has mainly focused on either the peer or parent context or on early and middle childhood. Moreover, our results imply that the two contexts are interdependent and that risk-effects of one context should be considered relative to protective factors of another context. Although girls were more likely than boys to have internalizing problems in early adolescence as a result of parental and peer rejection, there was no gender difference in the moderating effect of peer acceptance on parental rejection.
Relative Impact of Parental and Peer Relations

In accordance with previous research (Burgess et al. 2003; Khaleque and Rohner 2002; Rohner and Britner 2002) we found that when ignoring the peer context, parental rejection was associated with higher levels and parental acceptance was associated with lower levels of maladjustment in early adolescence. Similarly, ignoring the parent context, peer rejection was associated with higher levels and peer acceptance with lower levels of psychopathology in early adolescence (see also Buhs and Ladd 2001; Newcomb et al. 1993; Kupersmidt and Coie 1990; Parker and Asher 1987; Rubin et al. 2004). Interestingly, when the parent and peer context were considered simultaneously, the risk effect of peer rejection became smaller in relation to early adolescent externalizing problems and even disappeared in relation to early adolescent internalizing problems. In contrast to rejection, it was not parental acceptance but peer acceptance that remained strongly protective in association with early adolescent psychopathology when the two contexts were considered simultaneously.

Because inter-correlations between peer and parental factors were small, these findings are unlikely the result of multicollinearity. For the results on acceptance, the explanation may be found in processes of (partial) mediation. Parental acceptance might cause social competence in children which leads to acceptance by peers, and this might be linked to positive adjustment in early adolescence (in line with Rubin et al. 1998). This would mean that peer acceptance is the underlying mechanism for the relation between parental acceptance and adjustment in early adolescence. However, mediation as possible explanation does not hold for the findings on rejection, which show an opposite pattern.

Another process that might be going here is how normative the behavior of parents and peers is and linked to this how parental and peer behaviors are valued by early adolescents. As Furman and Buhrmester (1985) have shown, there is considerable overlap among the relationships that early adolescents have with their parents and peers in terms of affection, support, and intimacy. Still, because of the commonly held norm that children should get unconditional love and acceptance by their parents it might be that parental acceptance is taken for granted. This is implied by our finding that parental acceptance has no effect on early adolescent adjustment once peer acceptance is taken into account. Being accepted by parents might be considered normative whereas rejection by parents is not. As a result, parental rejection might be so hurtful because it contradicts the norm of receiving unconditional love and acceptance by parents. In comparing the standardized regression effects, the findings of the present study indeed suggest that being rejected by the primary attachment 
figures, parents, is more detrimental for adolescents' adjustment than rejection by peers. In order to state which context has the relatively highest impact for child development, however, future research should examine the influence of parent and peer relations with variables that are measured identically (e.g., child reports on parental and peer rejection or identical questions answered by parents and peers).

\section{Moderating Impact of Peer Relations}

We asked ourselves whether parent and peer relationships are interchangeable to a certain degree. With regard to this we tested whether potential harm effects in terms of behavioral or psychological maladjustment as a result of rejection in one context, can be overcome by being accepted in another context. The findings of this study show that peer acceptance was able to buffer the effects of parental rejection even though parental acceptance did not buffer the effects of peer rejection.

That positive peer relations can buffer for risky family relations is a finding that is consistent with research on interactions between family and peers in explaining victimization, internalizing problems, externalizing problems, and self-esteem (Bolger et al. 1998; Criss et al. 2002; Lansford et al. 2003; Rubin et al. 2004; Schwartz et al. 2000). Yet, most of these studies investigated elementaryschool aged children, whereas the findings of the current study show that the moderating role of positive peer relations also remains in early adolescence. In addition, as peers become of increasing importance in adolescence, their (moderating) impact on adolescent adjustment is likely to be larger with time as well. Moreover, Criss et al. (2002), although focusing on 5-year old children, concluded that the moderating effect of peer acceptance is unlikely the result of child temperament or social information processing serving as underlying mechanisms. Intervention and prevention in adolescent psychopathology might therefore benefit from including the classroom besides family members in their program. Nonetheless, despite the buffering role of peer acceptance, parental rejection still has a big impact on early adolescent externalizing and internalizing problems as is shown in Figs. 1 and 2.

Having said this, it might not be surprising that we found no risk-enhancing effect of rejection. That is, the negative effect of being rejected by parents was not larger when adolescents were also rejected by their peers (as compared to being accepted by peers), and vice versa. In other words, the negative effects of being rejected by parents and peers were not dependent on or conditioned by each other. This can most likely be explained by our earlier suggestions on the possible difference in importance of the two contexts. Apparently, being rejected by parents is already so detrimental for adolescents' behavioral adjustment that this negative effect is not noticeably enhanced by peer rejection. Though, this might change by the increase of age, when peers and other significant others (such as a romantic partner) become more and more important. The next step for future research then would be to see how the simultaneous effects of parents and peers affect late adolescence and young adulthood.

Although the effects of rejection and acceptance and their interactions were quite strongly related to early adolescent externalizing and internalizing problems, the interactions did not predict a change in externalizing and internalizing problems over a two-and-a-half year interval, nor did the main effects of parental acceptance and peer rejection. It must be said that the outcome measures were highly correlated over time (around 0.60 ). Yet, it is very likely that there is a transactional process going on (see Fanti et al. 2008), meaning that the relation between acceptance/rejection and behavior is bidirectional with effects that reinforce each other over time. One can imagine that when a child is being rejected it will develop problem behavior (as the current study shows), but that this child is therefore becoming less likeable and is thus being rejected even more, developing rejection-sensitivity and more problem behavior, and so on (see Veenstra et al. 2009). It would be interesting to see how these processes unfold from early adolescence into adulthood. This asks for longitudinal studies, allowing testing for cross-lagged paths between acceptance/rejection and behavior.

\section{Strengths and Limitations}

There are some shortcomings that should be considered when reviewing the findings of the present study. Firstly, although our measures were based on information from multiple informants (self, parents, and peers) which lowers the chance on inflated associations owing to shared method variance, there is also a limitation in this. Whereas our measures on parental acceptance and rejection were based on child-reports, measures of peer acceptance and rejection were based on peer-reports. Because the outcome measures consisted of both child and parent reports, this might have influenced the finding that the child reported parental relations had stronger effects on adolescent adjustment than the classmates reported peer relations. However, we believe that it is important to have perceived parenting measures instead of more objective measures. For instance, parental rejection will have a negative effect on children's outcomes especially (or maybe only) when these children experience rejection by their parents (see also Steinberg 2001). Unfortunately, we had no self-report measures on being accepted or rejected by peers. Still, the outcome measures were not only based on self-reports but also on parent 
reports, which mitigates the possible drawbacks of shared method variance.

Secondly, we only had peer information from a subsample of TRAILS. This subsample excluded children in special education and children who repeated a grade. As a result, the findings of this article can only be generalized to a somewhat advantaged population of early adolescents.

Thirdly, the measures of internalizing and externalizing problems were taken from the second wave of the TRAILS study. We were explicitly interested in whether the effects of rejection and acceptance still influence adolescents' adjustment two and a half years later. On balance, the time lag has both disadvantages and advantages. To some degree, the effects of acceptance and rejection two and a half years earlier may have worn out by the time psychopathology was assessed. That is, a change of school can bring a change in peer context and thus in peer rejection and acceptance (see Veenstra et al. 2009). This time lag may not only be a limitation, however. Rejection and acceptance experiences also need some time to work themselves out with regard to externalizing and internalizing problems. For the sake of completeness we also tested the hypotheses cross-sectionally, which produced exactly the same but somewhat stronger results as those reported in the present study. Unfortunately, we cannot test crosslagged paths with our data, but we were able to show that there is a link between these variables and an interaction between the parent and peer context.

Lastly, the effects of acceptance and rejection explained $13 \%$ of the variance in early adolescents' psychopathology. Obviously there are other variables from the individual, family, and social context which were not taken into account that may influence the development of externalizing and internalizing problems. However, the separate effects of the acceptance and rejection measures as well as their interactions were significant and do contribute to early adolescent psychopathology. This study thus helps but does not complete our understanding of the causes and triggers of problem behaviors in early adolescence.

Despite these limitations, the current study has major strengths compared to previous research on this topic. Former research has primarily focused on either peer or parent relations in relation to adjustment of, in most cases, young children. The current study examined the separate and simultaneous effects of parent and peer acceptance and rejection in late childhood on both externalizing and internalizing problems in early adolescence. Moreover, we also took into account the interdependence of the two contexts and tested cross-context interactions in order to answer the question whether attachment figures can substitute each other. To conclude, our results imply that the parent and peer contexts are interdependent and the highly negative impact of parental rejection on early adolescents' adjustment can be mitigated by being accepted by peers.

Acknowledgements This research is part of the TRacking Adolescents' Individual Lives Survey (TRAILS). Participating centers of TRAILS include various departments of the University Medical Center and University of Groningen, the Erasmus University Medical Center Rotterdam, the University of Utrecht, the Radboud Medical Center Nijmegen, and the Trimbos Institute, all in the Netherlands. Principal investigators are prof. dr. J. Ormel (University Medical Center Groningen) and prof. dr. F.C. Verhulst (Erasmus University Medical Center). TRAILS has been financially supported by various grants from the Netherlands Organization for Scientific Research NWO (Medical Research Council program grant GB-MW 940-38-011; ZonMW Brainpower grant 100-001-004; ZonMw Risk Behavior and Dependence grant 60-60600-97-118; ZonMw Culture and Health grant 261-98-710; Social Sciences Council medium-sized investment grant GB-MaGW 480-01006 and project grants GB-MaGW 457-03-018 and GB-MaGW 452-04314; NWO large-sized investment grant 175.010.2003.005); the Sophia Foundation for Medical Research (projects 301 and 393), the Dutch Ministry of Justice (WODC), and the participating universities. We are grateful to all adolescents, their parents and teachers who participated in this research and to everyone who worked on this project and made it possible.

Open Access This article is distributed under the terms of the Creative Commons Attribution Noncommercial License which permits any noncommercial use, distribution, and reproduction in any medium, provided the original author(s) and source are credited.

\section{References}

Achenbach, T. M. (1991a). Manual for the youth self-report and 1991 profile. Burlington: University of Vermont.

Achenbach, T. M. (1991b). Manual for the child behavior checklist/418 and 1991 profile. Burlington: University of Vermont.

Achenbach, T. M., McConaughy, S. H., \& Howell, C. T. (1987). Child adolescent behavioral and emotional problems: implications of cross-informant correlations for situational specificity. Psychological Bulletin, 101, 213-232.

Agnew, R. (2003). An integrated theory of the adolescent peak in offending. Youth \& Society, 34, 263-299.

Aiken, L. S., \& West, S. G. (1991). Multiple regression: Testing and interpreting interactions. Newbury Park: Sage.

Baumeister, R. F., \& Leary, M. R. (1995). The need to belong: desire for interpersonal attachments as a fundamental human motivation. Psychological Bulletin, 117, 497-529.

Bolger, K. E., Patterson, C. J., \& Kupersmidt, J. B. (1998). Peer relationships and self-esteem among children who have been maltreated. Child Development, 69, 1171-1197.

Bowlby, J. (1973). Attachment and loss, vol. 2. Separation: Anxiety and anger. New York: Basic.

Bronte-Tinkew, J., Moore, K. A., \& Carrano, J. (2006). The fatherchild relationship, parenting styles, and adolescent risk behaviors in intact families. Journal of Family Issues, 27, 850-881.

Buehler, C. (2006). Parents and peers in relation to early adolescent problem behavior. Journal of Marriage and the Family, 68, 109124.

Buhs, E. S., \& Ladd, G. W. (2001). Peer rejection as an antecedent of young children's school adjustment: an examination of mediating processes. Developmental Psychology, 37, 550-560. 
Bukowski, W. M., \& Hoza, B. (1989). Popularity and friendship: Issues in theory, measurement, and outcome. In T. J. Berndt \& G. W. Ladd (Eds.), Peer relations in child development (pp. 15-45). New York: Wiley.

Burgess, K. B., Marshall, P. J., Rubin, K. H., \& Fox, N. A. (2003). Infant attachment and temperament as predictors of subsequent externalizing problems and cardiac physiology. Journal of Child Psychology and Psychiatry, 44, 819-831.

Cohen, S., \& Wills, T. A. (1985). Stress, social support, and the buffering hypothesis. Psychological Bulletin, 98, 310-357.

Coie, J. D., Coppotelli, H., \& Dodge, K. A. (1982). Dimensions and types of social-status: A cross-age perspective. Developmental Psychology, 18, 557-570.

Collins, W. A., Maccoby, E. E., Steinberg, L., Hetherington, E. M., \& Bornstein, M. H. (2000). Contemporary research on parenting: the case for nature and nurture. American Psychologist, 55, 218 232.

Crick, N. R., \& Dodge, K. A. (1994). A review and reformulation of social information-processing mechanisms in children's socialadjustment. Psychological Bulletin, 115, 74-101.

Criss, M. M., Pettit, G. S., Bates, J. E., Dodge, K. A., \& Lapp, A. L. (2002). Family adversity, positive peer relationships, and children's externalizing behavior: a longitudinal perspective on risk and resilience. Child Development, 73, 1220-1237.

De Winter, A. F., Oldehinkel, A. J., Veenstra, R., Brunnekreef, J. A., Verhulst, F. C., \& Ormel, J. (2005). Evaluation of non-response bias in mental health determinants and outcomes in a large sample of pre-adolescents. European Journal of Epidemiology, 20, 173-181.

Fanti, K. A., Henrich, C. C., Brookmeyer, K. A., \& Kuperminc, G. P. (2008). Toward a transactional model of parent-adolescent relationship quality and adolescent psychological adjustment. The Journal of Early Adolescence, 28, 252-276.

Fotti, S. A., Katz, L. Y., Afifi, T. O., \& Cox, B. J. (2006). The associations between peer and parental relationships and suicidal behaviours in early adolescents. Canadian Journal of Psychiatry, 51, 698-703.

Fuligni, A. J., \& Eccles, J. S. (1993). Perceived parent-child relationships and early adolescents' orientation toward peers. Developmental Psychology, 29, 622-632.

Furman, W., \& Buhrmester, D. (1985). Children's perceptions of the personal relationships in their social networks. Developmental Psychology, 21, 1016-1024.

Gauze, C., Bukowski, W. M., AquanAssee, J., \& Sippola, L. K. (1996). Interactions between family environment and friendship and associations with self-perceived well-being during early adolescence. Child Development, 67, 2201-2216.

Giordano, P. C. (1995). The wider circle of friends in adolescence. American Journal of Sociology, 101, 661-697.

Greenberg, M. T., Siegel, J. M., \& Leitch, C. J. (1983). The nature and importance of attachment relationships to parents and peers during adolescence. Journal of Youth and Adolescence, 12, 373386.

Hale, W. W., Van Der Valk, I., Engels, R., \& Meeus, W. (2005). Does perceived parental rejection make adolescents sad and mad? The association of perceived parental rejection with adolescent depression and aggression. Journal of Adolescent Health, 36, 466-474.

Hankin, B. L., \& Abramson, L. Y. (2001). Development of gender differences in depression: an elaborated cognitive vulnerabilitytransactional stress theory. Psychological Bulletin, 127, 773-796.

Harris, J. R. (1995). Where is the child's environment? A group socialization theory of development. Psychological Review, 102, $458-489$.

Hartup, W. W. (1996). The company they keep: friendships and their developmental significance. Child Development, 67, 1-13.
Huisman, M., Oldehinkel, A. J., de Winter, A., Minderaa, R. B., de Bildt, A., Huizink, A. C., et al. (2008). Cohort profile: the dutch tracking adolescents individual lives survey; TRAILS. International Journal of Epidemiology, 37, 1227-1235.

Kerns, K. A., Klepac, L., \& Cole, A. K. (1996). Peer relationships and preadolescents' perceptions of security in the child-mother relationship. Developmental Psychology, 32, 457-466.

Khaleque, A., \& Rohner, R. P. (2002). Perceived parental acceptancerejection and psychological adjustment: a meta-analysis of crosscultural and intracultural studies. Journal of Marriage and the Family, 64, 54-64.

Kupersmidt, J. B., \& Coie, J. D. (1990). Preadolescent peer status, aggression, and school adjustment as predictors of externalizing problems in adolescence. Child Development, 61, 1350-1362.

Laird, R. D., Pettit, G. S., Dodge, K. A., \& Bates, J. E. (2005). Peer relationship antecedents of delinquent behavior in late adolescence: is there evidence of demographic group differences in developmental processes? Development and Psychopathology, 17, 127-144.

Lansford, J. E., Criss, M. M., Pettit, G. S., Dodge, K. A., \& Bates, J. E. (2003). Friendship quality, peer group affiliation, and peer antisocial behavior as moderators of the link between negative parenting and adolescent externalizing behavior. Journal of Research on Adolescence, 13, 161-184.

Loeber, R., \& Stouthamerloeber, M. (1986). Family factors as correlates and predictors of juvenile conduct problems and delinquency. Crime and Justice: A Review of Research, 7, 29149.

Markus, M. T., Lindhout, I. E., Boer, F., Hoogendijk, T. H. G., \& Arrindell, W. A. (2003). Factors of perceived parental rearing styles: the EMBU-C examined in a sample of Dutch primary school children. Personality and Individual Differences, 34, 503-519.

Muris, P., Meesters, C., \& van Brakel, A. (2003). Assessment of anxious rearing behaviors with a modified version of "Egna Minnen Betraffande Uppfostran" questionnaire for children. Journal of Psychopathology and Behavioral Assessment, 25, 229-237.

Newcomb, A. F., Bukowski, W. M., \& Pattee, L. (1993). Childrens peer relations: a meta-analytic review of popular, rejected, neglected, controversial, and average sociometric status. Psychological Bulletin, 113, 99-128.

Nolen-Hoeksema, S., \& Girgus, J. S. (1994). The emergence of gender differences in depression during adolescence. Psychological Bulletin, 115, 424-443.

Parker, J. G., \& Asher, S. R. (1987). Peer relations and later personal adjustment: are low-accepted children at risk? Psychological Bulletin, 102, 357-389.

Parker, J. G., \& Asher, S. R. (1993). Friendship and friendship-quality in middle childhood: links with peer group acceptance and feelings of loneliness and social dissatisfaction. Developmental Psychology, 29, 611-621.

Patrick, H., Knee, C. R., Canevello, A., \& Lonsbary, C. (2007). The role of need fulfillment in relationship functioning and wellbeing: a self-determination theory perspective. Journal of Personality and Social Psychology, 92, 434-457.

Patterson, G. R., Reid, J. B., \& Dishion, T. J. (1992). Antisocial boys. Eugene: Castalia.

Patterson, G. R., Forgatch, M. S., Yoerger, K. L., \& Stoolmiller, M. (1998). Variables that initiate and maintain an early-onset trajectory for juvenile offending. Development and Psychopathology, 10, 531-547.

Pettit, G. S., \& Arsiwalla, D. D. (2008). Commentary on special section on "bidirectional parent-child relationships": the continuing evolution of dynamic, transactional models of parenting and youth. Journal of Abnormal Child Psychology, 36, 711718 . 
Raja, S. N., McGee, R., \& Stanton, W. R. (1992). Perceived attachments to parents and peers and psychological well-being in adolescence. Journal of Youth and Adolescence, 21, 471-485.

Robertson, J. F., \& Simons, R. L. (1989). Family factors, self-esteem, and adolescent depression. Journal of Marriage and the Family, $51,125-138$.

Rohner, R. P. (2004). The parental "acceptance-rejection syndrome": universal correlates of perceived rejection. American Psychologist, $59,827-840$.

Rohner, R. P., \& Britner, P. A. (2002). Worldwide mental health correlates of parental acceptance-rejection: review of crosscultural and intracultural evidence. Cross-Cultural Research, $36,16-47$.

Rothbaum, F., \& Weisz, J. R. (1994). Parental caregiving and child externalizing behavior in nonclinical samples: a meta-analysis. Psychological Bulletin, 116, 55-74.

Rubin, K. H., Bukowski, W., \& Parker, J. G. (1998). Peer interactions, relationships, and groups. In N. Eisenberg \& W. Damon (Eds.), Handbook of child psychology: Vol 3. Social, emotional, and personality development (5th ed., pp. 619-700). New York: Wiley.

Rubin, K. H., Dwyer, K. M., Booth-LaForce, C., Kim, A. H., Burgess, K. B., \& Rose-Krasnor, L. (2004). Attachment, friendship, and psychosocial functioning in early adolescence. Journal of Early Adolescence, 24, 326-356.

Schwartz, D., Dodge, K. A., Pettit, G. S., \& Bates, J. E. (2000). Friendship as a moderating factor in the pathway between early harsh home environment and later victimization in the peer group. Developmental Psychology, 36, 646-662.

Sentse, M., Dijkstra, J. K., Lindenberg, S., Ormel, J., \& Veenstra, R. (2009a). The delicate balance between parental protection, unsupervised wandering, and adolescents' autonomy and its relation with antisocial behavior. The TRAILS Study. International Journal of Behavioral Development. (forthcoming)

Sentse, M., Veenstra, R., Lindenberg, S., Verhulst, F. C., \& Ormel, J. (2009b). Buffers and risks in temperament and family for early adolescent psychopathology: generic, conditional, or domainspecific effects? The TRAILS study. Developmental Psychology, $45,419-430$.

Steinberg, L. (2001). We know some things: parent-adolescent relationships in retrospect and prospect. Journal of Research on Adolescence, 11, 1-19.

Twenge, J. A., \& Nolen-Hoeksema, S. (2002). Age, gender, race, socioeconomic status, and birth cohort differences on the children's depression inventory: a meta-analysis. Journal of Abnormal Psychology, 111, 578-588.

Veenstra, R., Lindenberg, S., Oldehinkel, A. J., De Winter, A. F., Verhulst, F. C., \& Ormel, J. (2005). Bullying and victimization in elementary schools: a comparison of bullies, victims, bully/ victims, and uninvolved preadolescents. Developmental Psychology, 41, 672-682.

Veenstra, R., Lindenberg, S., Verhulst, F. C., \& Ormel, J. (2009). Childhood-limited versus persistent antisocial behavior: why do some recover and others do not? The TRAILS Study. Journal of Early Adolescence, 29. doi:10.1177/0272431608325501.

Verhulst, F. C., \& Van der Ende, J. (1992). Agreement between parents reports and adolescents self-reports of problem behavior. Journal of Child Psychology and Psychiatry, 33, 1011-1023.

Verhulst, F. C., \& Achenbach, T. M. (1995). Empirically based assessment and taxonomy of psychopathology: cross-cultural applications. European Child \& Adolescent Psychiatry, 4, 61-76. 